\title{
LITERATURA DE VIAGEM - MARTIUS, SPIX E ESCHWEGE SOBRE O BRASIL
}

\author{
TRAVEL LITERATURE - MARTIUS, SPIX AND \\ ESCHWEGE ON BRAZIL
}

Ulrike Schröder*

\begin{abstract}
RESENHA
AUGUSTIN, Günther. Literatura de Viagem na época de João VI. Belo Horizonte: Editora UFMG, 2009.
\end{abstract}

Como gênero literário, a literatura de viagem engloba os relatos de viagem que não são apenas lidos como textos factuais informativos, mas como produtos de um processo de writing culture como os etnógrafos o chamam, destacando com esse termo, o processo da própria escrita na descrição dos fatos observados. Numa simbiose quase paradigmática, essa abordagem foi assimilada pela teoria literária que passa a dar mais atenção aos aspectos culturais nos textos literários. Sem cair nos equívocos dos chamados 'estudos culturais', a análise de textos como constructos ou codificações culturais representa um método integrativo, tendo como base a visão da língua como expressão da cultura, a cultura como expressão do agir, sentir, pensar, falar e escrever, levando em conta, a partir desses elementos, a literaricidade dos textos. $O$ texto passa a ser visto no contexto de seus aspectos tropológicos, metonímicos e metafóricos, bem como seu balançar entre fato e ficção. A literatura de viagem constitui um objeto bastante adequado para este tipo de análise e o livro Literatura de Viagem na época de João VI demonstra isso de forma exemplar nos dois sentidos: é um exemplo do tipo de análise integra-

* Doutora em Comunicação Social pela Universidade de Essen, professora Adjunta da Faculdade de Letras da UFMG. 
da de textos culturais e demonstra isso em textos da literatura de viagem de autoria de viajantes alemães no Brasil na segunda década do século XIX.

Quando em 1808 a corte portuguesa veio ao Brasil, o imperador colonizador viu-se colonizado e logo abriu as portas do país para o comércio e a entrada de visitantes estrangeiros, entre eles Wilhelm Ludwig von Eschwege, o Barão, como foi chamado em Minas Gerais, engenheiro a serviço da coroa, e Johann Baptist von Spix, zoólogo, junto com Carl Friedrich Philipp von Martius, botânico, em missão científica acompanhando o séquito da noiva de Dom Pedro I, a arquiduquesa Leopoldina. Como muitos outros viajantes estrangeiros do velho mundo, eles deixaram relatos de suas viagens para a posterioridade, tornando-se autores de um novo descobrimento do Brasil. A disputa entre os diferentes discursos sobre o Brasil se reflete na história da edição dos relatos desses viajantes, mais especificamente dos de Eschwege. Seu Pluto Brasiliensis foi publicado na 'Coleção Reconquista do Brasil', uma coleção de relatos de viagem predominantemente de autoria estrangeira. O clássico Viagem pelo Brasil de Spix e Martius faz parte da segunda série da mesma coleção. Já as traduções das duas obras de Eschwege analisadas no livro foram apresentadas ao público brasileiro durante os últimos quinze anos: Brasil: Novo Mundo foi publicado em 1996 (vol. I) e 2000 (vol. II), e Jornal do Brasil, em 2002.

Como indica o título, Literatura de Viagem na época de João VI trata principalmente dos relatos de viagem daquela década pré-independência do Brasil e sua relevância para a formação do imaginário cultural brasileiro. Mas mesmo assim, o aspecto histórico é apenas uma das múltiplas facetas analisadas nos textos dos viajantes. O livro do professor Günther Augustin, da Universidade Federal de Minas Gerais, pode ser visto como um guia para mostrar as múltiplas facetas desses textos de literatura de viagem. Eschwege escreve sem saber escrever bem, como caminhante olhando na "Feldperspektive ... wie diese Perspektive innerhalb der Kognitionswissenschaften bezeichnet worden ist." (WAGNER, 2005: 194), e impulsionado pelo que o autor chama um Schreibtrieb, ele transforma seu olhar em escrita e descreve não apenas a árdua realidade mineira, mas chega a momentos poéticos também. Spix e Martius aplicam o modelo estético do quadro de natureza de Alexander von Humboldt, enquanto Martius transforma fatos em ficção em seu romance de idéias sobre o encontro do europeu com o mundo amazônico.

Nas leituras dos relatos, Augustin baseia suas análises integrativas nos conceitos cultura, literatura e discurso, insistindo no seu slogan da cultura como 
texto e o texto como discurso. Na definição do seu principal instrumento analítico, a identificação da discursividade dos textos, recorre ao pai da crítica do pensamento ocidental, Friedrich Nietzsche. No perspectivismo simbólico de Nietzsche, o olhar é sempre seletivo e resulta em um falar seletivo. Assim, a discursividade de um texto é a sua perspectividade historicamente formada. Utilizando os conceitos de discurso e discursividade, ele analisa como Eschwege bem como Spix e Martius escreveram, mostrando a discursividade a partir da seletividade do seu olhar e a transformação dos olhares em escrita, isto é, a sua textualização, tendo como ponto de partida as perguntas: o que e por que nossos viajantes escreveram, e qual o significado dos seus textos como memória cultural. Desta forma, o autor identifica uma multiplicidade de discursos: o do naturalista, cientista, utilitarista, indianista, ufanista, idealista, realista, romântico, universalista, monarquista, crítico, cristão, humboldtiano e kantiano. A variedade atesta olhares mais diferenciados do que a visão, em geral, dicotômica identificada pela maioria dos comentários a respeito dos viajantes naturalistas do velho mundo. Vendo seus olhares e lendo seus textos, uma análise crítica revela que esses autores articulam vozes do seu tempo e espaço europeus, escrevendo para seus leitores cujos gostos, horizontes e interesses os editores sabiam alimentar. Nesse sentido, registram mais coisa européia do que as do novo mundo, na medida em que hierarquizaram o visto às suas categorias e conceitos: epistemologia e estética clássicas, ciência e economia expansionistas, burguesia de origem européia, o encontro do Ocidente com o Oriente, do alpino com o tropical, o mundo físico e metafísico, o paraíso perdido. $\mathrm{O}$ autor contextualiza tanto a gênese da escrita quanto a sua leitura para entender como ambas foram e estão sendo determinadas pela formação discursiva dos autores e dos leitores.

Todo Capítulo 1 é dedicado à descrição dessa forma discursiva de maneira inovadora e instrutiva. Percebe-se a intenção do autor de apresentar uma visão da cultura alemã da época, para que o leitor entenda qual a visão de mundo esses viajantes tinham ao chegarem aqui, pois os relatos refletem este olhar europeu, que era bem mais complexo do que um simples olhar imperialista. O livro relata por exemplo duas visitas de Martius à casa de Goethe, em Weimar. Durante o jantar o assunto era a multiplicidade de raças humanas, pretos, marrons, amarelos e brancos. Chegou-se à pergunta se todos os homens teriam uma única descendência no casal Adão e Eva. Goethe nega esta hipótese. Martius admite que gostaria de deixar-se convencer por esta opinião como naturalista; entretanto, como bom cristão teria dificuldade em assumir uma opinião que não fosse em conformidade com 
os enunciados da Bíblia. Johann Gottfried Herder poderia ter ajudado nesta escolha difícil. Herder (apud Augustin, 2009: 29) ensinou que, como o pesquisador da natureza, o historiador deve proceder sem preconceitos e opinou: "O negro tem tanto direito de considerar o branco uma deformação, uma barata, como o branco considerá-lo uma besta, um animal preto." Além de valorizar o caráter nacional de cada povo e condenar ao mesmo tempo qualquer nacionalismo exagerado, ele combateu a arrogância dos europeus sobre outros povos e raças, combateu o imperialismo e o colonialismo e previu que, talvez, um dia, os colonizados triunfariam: "Estamos colocando as correntes em vocês, com as quais vocês vão nos arrastar." São opiniões pouco conhecidos do velho mundo do iluminismo que o livro revela na descrição diferenciada da formação discursiva do olhar europeu da época. A menção de Herder reflete a redescoberta deste pensador importante durante a última década. BoRsCHE (2006: 139) affirma que "Das Klima scheint heute günstiger zu sein als je zuvor in den vergangenen zweihundert Jahren für eine (Neu-)-Eröffnung des Gesprächs der ungleichen Zeitgenossen." Como o autor destaca a influência do pensamento kantiano, poderia melhor ter mostrado como Herder não apenas valorizou a individualidade das etnias, mas ofereceu uma visão epistemológica alternativa àquela de Kant, individualizando a razão como histórica e geograficamente determinada. Daria conta também do pensamento lingüístico de Herder que representa para BORSCHE (2006: 141) “ eine Überwindung des linguistic turn ..." entendido no sentido de BöHME (2005: XII) como "Aufruf zur Erinnerung an verdrängtes oder vergessenes Wissen".

No Capítulo 2 são identificados, através de cortes discursivos, por se tratar de relatos fragmentados, os principais discursos representados nos textos de Eschwege em seus livros publicados no Brasil. Aplicando sua análise integrativa, o autor mostra seus leitores como Eschwege e seus textos têm algo de híbrido, fugindo em alguns aspectos dos esquemas preestabelecidos pelas análises sumárias dos relatos de viagem que compõem a literatura dos viajantes, mostrando como o olhar crítico do viajante o levou a juízos, às vezes, arrogantes eurocentristas e desconcertantes para o público brasileiro. Ao mesmo tempo, seus textos expressam compreensão e simpatia para com o Brasil como país emergente. Como viajante intercultural, Eschwege atravessou fronteiras geográficas, nacionais, sociais, históricas e culturais, deslocando-se para outros locais, estados, países, passando por épocas históricas, regimes políticos e econômicos, mentalidades e domínios lingüísticos diferentes. $\mathrm{Na}$ análise da construção da escrita, o leitor pode perceber como o paradoxal e a ironia, apenas tímida e vagamente presente no início, são 
articulados com mais evidência ao longo dos relatos, principalmente a figura do ouro preto, metáfora subentendida para lembrar que o ouro só vale, só brilha por mediação do preto, que não há branco sem preto e que o colonizador é seu próprio colonizado.

Enquanto Eschwege escreveu seus relatos sem maiores pretensões literárias, Spix e Martius redigiram Viagem pelo Brasil como narrativa literária na tradição estética científica de Alexander von Humboldt e sua proposta de 'quadro da natureza'. Como mostra o Capítulo 3, o relato dos dois bávaros é, ao mesmo tempo, um relato e literatura, história e narrativa, fato e ficção, físico e metafísico, como Willi Bolle diz quando comparou Spix e Martius com João Guimarães Rosa. Em termos de discursividade, reconhecem-se elementos dos discursos da Europa civilizada, do encontro do Ocidente com o Oriente, da alma, do paraíso perdido, da terceira dimensão cósmica, do sagrado, da harmonia, do idealista, do moralista e do colonizador expansionista. $\mathrm{O}$ autor procura mostrar como esses discursos são distribuídos ao longo do relato de Viagem pelo Brasil. Muito disso foi influenciado por Alexander von Humboldt que propôs e executou uma síntese não apenas entre um modelo quantificador e organicista, mas também entre realista e idealista estético. O ideal da descrição de Humboldt é o quadro de natureza textualizada que representaria a ordem harmônica do mundo. Um exemplo da "preconceituação" da percepção estética dos viajantes é a descrição dos troncos das palmeiras como colunas que a natureza constrói remetendo à arquitetura classicista. A estetização da natureza se manifesta mais claramente ainda quando Martius faz uma distinção entre a importância objetiva e o puro gozo da natureza, entre o objetivo, realcientífico, lógico, e o subjetivo, poético, psicológico seguindo assim as orientações geopsíquicas de Humboldt.

No quarto capítulo o autor aproveitou-se da rara constelação de ter, lado ao lado, um relato de viagem real e um ficcional. O livro Frey Apollonio, escrita, mas nunca publicado por Martius, se diferencia do relato Viagem pelo Brasil por duas marcas: chama-se romance e começa como sonho. A rigor, todo o romance é um sonho que conta a história da viagem pelo Amazonas, transformando em fábula o trecho da viagem entre Pará e Cupati. Distante dos costumes e da cultura europeus, o protagonista quer conhecer a América e viajar ao encontro dos selvagens no interior do continente. $\mathrm{O}$ sonho como não-realidade, fantasia, manifestação do inconsciente etc. tem um potencial de funções das quais Martius se aproveita: desautoriza sua autoria, articula uma voz interior, abre uma nova dimensão de experiência, inclusive a ilusão romântica da criação de outra realidade, e usa um 
modo de imaginar o inconsciente. Como imaginação, a linguagem do sonho é puramente visual, estética, não-discursiva, isto é, poética. Para todas essas potencialidades do sonho encontram-se evidências em Frey Apollonio. Ao mesmo tempo, o romance é em grande parte discursivo, apresentando uma sequiência de reflexões que se desenrolam nos diálogos entre os personagens durante a viagem pelas águas do Amazonas. A água como símbolo da força criadora e do fluxo da vida parece alimentar a viagem espiritual. Essa viagem, que inclui, na narrativa do monge, uma história dentro da história, leva o leitor a três continentes, separados e unidos ao mesmo tempo pelas águas. E como as águas, os próprios discursos unem e separam-se simultaneamente, cruzando-se, opondo-se e sobrepondo-se, gerando sempre seus próprios contradiscursos e ao mesmo tempo procurando aproximar-se e fundir se, semelhantemente às ondas nas quais os viajantes flutuam, batendo e rebatendo.

Em termos epistemológicos e epistêmicos, utilizando o conceito de M. Foucault, o autor situa os viajantes e seus relatos em uma fase de transição da episteme clássica para a moderna, uma fase que é marcada pelo criticismo kantiano. Eschwege se revela como crítico, enquanto Spix e Martius seriam pré-críticos. O intertexto de Kant está, embora implicitamente, evidente em Eschwege. Spix e Martius são mais explícitos, mencionando nomes, Kant mais de uma vez, mas Jacobi, crítico de Kant na época, também. A relativa novidade do conceito kantiano de espaço, como forma a priori da intuição, faz com que Eschwege procure uma definição de espaço em termos de movimento e tempo, na sua descrição da baía de Guanabara. Já Spix e Martius, visualizam o espaço cósmico, tridimensional, mar, terra e céu formando uma totalidade que teria no Equador sua faixa de equilíbrio harmonioso.

Com sua sensibilidade aguda para os mecanismos da língua, o autor focaliza esse aspecto na análise dos textos também. Como todo viajante, os três percebem a relação entre língua e cultura na compreensão do país e do povo visitado. Se o discurso é uma fala socialmente construída, cada língua é o discurso da sua cultura, no sentido da língua como discurso. Eschwege diz que precisa conviver muito tempo para entender um povo. Como viajante transcultural, pratica a tradução cultural. Spix e Martius observam nos seus estudos lingüísticos que a língua dos índios corresponde à sua cultura, não há correspondências para seus conceitos europeus e, quando há, foram implantados pelos missionários. Sua preocupação com a denominação parece refletir o medo da demonização da fala que detectaram nos índios. 
Resumindo, o livro Literatura de Viagem na época de João VI faz uma releitura crítica dos textos dos viajantes naturalistas e romancistas. Mostra a discursividade dos textos, identificando elementos dos discursos da Europa civilizada, do encontro do Ocidente com o Oriente, da alma, do paraíso perdido, da terceira dimensão cósmica, do sagrado, da harmonia, do idealista, do moralista e do colonizador expansionista. Analisa como Eschwege era um viajante híbrido, transcultural, vivendo nos entre-lugares, atravessando fronteiras nacionais, naturais, culturais, linhas de guerra e rios divisórios. Mostra ainda como Martius, no ponto mais ocidental da sua viagem, em um "Ocidente ao ocidente do Ocidente" (definição do Brasil que Augustin encontrou em Caetano Veloso no seu livro Verdade Tropical), se acha no fim de uma peregrinação, que, no fundo, começou no Oriente, no berço da cristandade. Em suas reflexões espelham-se Ocidente e Oriente, e o olhar europeu se dobra sobre si mesmo, agora sobre um Ocidente ao oriente do novo Ocidente, demonstrando o jogo da dialética da alteridade e da alternância dos discursos que o livro explora.

\section{Referências}

BÖHME, Hartmut (Hrsg.). Topographien der Literatur. Stuttgart/Weimar: Metzler, 2005.

BORSCHE, Tilmann (Hrsg.). Herder im Spiegel der Zeiten. München: W. Fink Verlag, 2006.

ESCHWEGE, W. L. von. Brasil, Novo Mundo. Tradução de Domício de Figueiredo Murta. Belo Horizonte: Centro de Estudos Históricos e Culturais/Fundação João Pinheiro, 1996, v. 1.

ESCHWEGE, W. L. von. Brasil, Novo Mundo. Tradução de Myriam Ávila. Belo Horizonte: Fundação João Pinheiro/Centro de Estudos Históricos e Culturais, 2000, v. 2.

ESCHWEGE, W. L. von. Jornal do Brasil, 1811-1817. Tradução de Friedrich E. Renger, Tarcísia L. Ribeiro e Günter Augustin. Belo Horizonte: Fundação João Pinheiro/Centro de Estudos Históricos e Culturais, 2002.

MARTIUS, C. F. P. von. Frey Apollonio um romance do Brasil. Organização e tradução de Erwin Theodor. São Paulo: Brasiliense, 1992. 
SCHRÖDER, U. Literatura de viagem

SPIX, J. B. von. Viagem pelo Brasil: 1817-1820. SPIX e MARTIUS. Tradução de Lúcia Furquim Lahmeyer. Belo Horizonte, Itatiaia/São Paulo, Editora da Universidade de São Paulo: 1981, v. 1-3.

WAGNER, Kirsten. Im Dickicht der Schritte. In: BÖHME, Hartmut (Hrsg.). Topographien der Literatur. Stuttgart/Weimar: Metzler, 2005, 174-206. 